\title{
GUARDA COMPARTILHADA: UM CAMINHO PARA INIBIR A ALIENAÇÃO PARENTAL?
}

\section{SHARED CUSTODY: A WAY TO INHIBIT PARENTAL ALIENATION?}

\begin{abstract}
EDWIRGES ELAINE RODRIGUES
Graduada em Direito, Faculdade de Direito de Franca; especialista em Direito Processual Civil, FCHS/UNESP; membro de grupo de pesquisa, CNPq; membro do IBDFAM. edwirges_elaine@yahoo.com.br
\end{abstract}

MARIA AMÁLIA DE FIGUEIREDO PEREIRA ALVARENGA Coordenadora do Conselho do Curso de graduação em Direito da Unesp (2011-2014). Graduação em Direito pela Faculdade de Direito de Franca (1984), Mestrado em DIREITO - FHDSS (1994) e Doutorado em DIREITO - FHDSS (1999). Coordenadora dos Programas de Mestrado em Direito Público e Direito Empresarial na Unifran (2002- 2003). Líder de pesquisa da CNPQ e membro do IBDFAM. draamaliaalvarenga@yahoo.com.br

\begin{abstract}
RESUMO
Esta pesquisa resume-se ao instituto jurídico da Guarda Compartilhada, uma das modalidades de guarda presente no ordenamento jurídico brasileiro, introduzida pela Lei $\mathrm{n}^{\circ} 11.698 / 2008$. Contudo, muito há de se discutir a respeito deste instituto, uma vez que a guarda compartilhada exige alguns requisitos que muitas vezes impedem sua aplicação, pois só trará vantagens caso haja perfeita harmonia na relação entre os genitores. A lei que trata da alienação parental, $n^{\circ} 12.318 / 2010$, também é abordada por este artigo. Esta legislação prevê a mudança de guarda para guarda compartilhada como uma das principais sanções para inibir a prática de alienação parental. Entretanto, cada caso deve ser analisado de forma particular, tendo em vista que o principal sujeito de toda esta disputa é o filho, que deve ser protegido pelo princípio do melhor interesse da criança e do adolescente.
\end{abstract}

Palavras-chave: alienação parental; direito de família; guarda compartilhada; harmonia; instituto da guarda.

\begin{abstract}
This research summarizes the legal institution of joint custody, one of the custody modalities present in the Brazilian juridical ordering, introduced by the law number $11.698 / 2008$. However, there is much to discuss about this institute, considering that the joint custody requires certain requirements that often prevents its application, therefore, only bring benefits if there is perfect harmony in the relationship between the parents. The law which deals with parental alienation, number $12.318 / 2010$, is also approached by this article, this legislation brings the change of custody to joint custody as the main penalties to inhibit the practice of parental alienation. However, each case must to be analyzed in a particular way, considering that the main subject of this whole dispute is the child who must be protected by the principle of the best interests of the child and adolescent.
\end{abstract}

Keywords: family law; harmony; institute of the custody; parental alienation; shared custody. 


\section{SUMÁRIO}

INTRODUÇAO; 1 PODER FAMILIAR; 2 INSTITUTO DA GUARDA E SUAS MODALIDADES; 3 DIFERENÇAS ENTRE GUARDA ALTERNADA E GUARDA COMPARTILHADA; 4 PRINCÍPIO DO MELHOR INTERESSE DA CRIANÇA E DO ADOLESCENTE; 5 VANTAGENS DA GUARDA COMPARTILHADA; 6 DESVANTAGENS DA GUARDA COMPARTILHADA; 7 ALIENAÇÃO PARENTAL; 8 GUARDA COMPARTILHADA COMO FORMA DE INIBIR A ALIENAÇÃO PARENTAL; CONCLUSÃO; REFERÊNCIAS.

\section{INTRODUÇÃO}

O direito de família é de extrema importância na vida dos cidadãos brasileiros, que têm suas questões familiares abordadas tanto pelo Código Civil quanto pelo Estatuto da Criança e do Adolescente, e em especial pela Constituição Federal.

0 direito brasileiro, sobretudo o direito de família, vem enfrentando diversas transformações na contemporaneidade, atendendo aos anseios da sociedade que se transforma a cada dia.

Se na antiguidade o casamento era indissolúvel, hoje, o divórcio pode ser decretado sem a exigência da discussão da culpa pelo rompimento da conjugalidade.

$E$, é neste contexto de separações que surge o tema deste artigo, pois o instituto da guarda está intimamente relacionado com a dissolução do casamento em que há filhos menores.

Existem duas modalidades de guarda que são abordadas pela legislação brasileira.

A guarda Uniparental ou Unilateral, art. 1.583, do Código Civil, é considerado o modelo tradicional e mais utilizado em nosso ordenamento jurídico. Neste tipo de guarda, o menor fica com um dos pais em residência fixa, e ao outro genitor é conferido o direito de visitas.

Em junho de 2008, a Lei $n^{\circ} 11.698$ alterou os art. 1.583 e 1.584 do Código Civil para instituir e disciplinar a Guarda Compartilhada, que há tempos era aplicada, entretanto sem uma regulamentação legal.

Este modelo de guarda consiste em um sistema no qual os filhos e pais separados mantêm uma convivência harmoniosa, e todas as decisões referentes à prole são tomadas em conjunto com a opinião de ambos os genitores. 
Embora seja o modelo recomendado pela legislação, a guarda compartilhada exige alguns requisitos que muitas vezes impedem sua aplicação, pois a guarda conjunta só trará vantagens caso haja perfeita harmonia na relação entre os genitores, sendo que todas as decisões acerca da vida dos filhos deverão ser tomadas em conjunto, além de serem consentidas tanto pelo pai como pela mãe.

Sabe-se que com o advento do divórcio, muitos ex-casais não conseguem manter um relacionamento amigável dificultando, assim, a aplicação da guarda compartilhada.

É importante frisar que no contexto das disputas pela guarda dos filhos, tem ocorrido um ato extremamente prejudicial às crianças/adolescentes, este ato é denominado de alienação parental, que pode ocasionar a Síndrome da Alienação Parental (SAP).

Haja vista o envolvimento da prática de alienação parental em muitos casos onde é aplicada a guarda unilateral, a Lei que trata desta alienação (Lei $n^{\circ} 12.318 / 2010$ ) traz, como forma de inibir este ato, a mudança da guarda uniparental para a modalidade de guarda compartilhada.

Desta forma, com um estudo mais detalhado a respeito da guarda compartilhada, chegar-se-á a uma conclusão a respeito deste tema.

\section{PODER FAMILIAR}

O poder familiar compreende a reunião dos direitos e deveres dos pais em relação aos filhos menores não emancipados, conforme preceitua o art. 1.630 do Código Civil ${ }^{1}$.

As crianças e adolescentes são incapazes de prover suas necessidades e reger seus bens, necessitando que alguém o faça. Os direitos e obrigações visam à formação integral desse ente, formação física, mental, moral, espiritual, social, ou seja, tudo o que necessário for para uma vivência sadia, realizada e completa.

Maria Helena Diniz assim define o poder familiar:

Conjunto de direitos e obrigações, quanto à pessoa e bens do filho menor não emancipado, exercido, em igualdade de condições, por ambos os pais, para que possam desempenhar os encargos que a norma jurídica lhes impõe, tendo em vista o interesse e a proteção do filho. ${ }^{2}$

\footnotetext{
${ }^{1}$ Art. 1.630, Código Civil, "Os filhos estão sujeitos ao poder familiar, enquanto menores."

2 DINIZ, Maria Helena. Curso de direito civil brasileiro: direito de família. v.5. 25. ed. São Paulo: Saraiva, 2010 , p. 564.
} 
Busca-se, através do significado do instituto do poder familiar, que haja na família a convivência e a participação dos membros do grupo, sendo fundamental o diálogo, a compreensão e o entendimento. entre os pais:

Por fim, o Estatuto da Criança e do Adolescente trata da igualdade de poderes

Art. 21: 0 poder familiar será exercido, em igualdade de condições, pelo pai e pela mãe, na forma do que dispuser a legislação civil, assegurado a qualquer deles o direito de, em caso de discordância, recorrer à autoridade judiciária competente para a solução da divergência.

\section{INSTITUTO DA GUARDA E SUAS MODALIDADES}

A palavra guarda, que encontra raízes no antigo alemão wargen (guarda, espera), no inglês warden (guarda), e no francês garde, é empregada em sentido genérico para exprimir proteção, observância, vigilância, segurança ou administração, um direito/dever que os pais estão incumbidos de exercer em favor de seus filhos. ${ }^{3}$

Conforme art. 1.634, inciso II, do Código Civil ${ }^{4}$, e art. $21^{5}$ e $22^{6}$ do Estatuto da Criança e do Adolescente, o vocábulo guarda está intimamente relacionado ao poder familiar, conferindo caráter de posse do menor.

Neste sentido, preceitua o art. 33, § $1^{\circ}$, do Estatuto da Criança e do Adolescente, "A guarda destina-se a regular a posse de fato, podendo ser deferida, liminar ou incidentalmente, nos procedimentos de tutela e adoção, exceto no de adoção por estrangeiros”.

Por fim, a guarda integra o conjunto de direitos e obrigações que o ordenamento jurídico impõe aos pais em relação à prole.

Com a decorrência da maternidade/paternidade, surge o primeiro modelo de guarda, o qual não é judicial, mas sim natural.Este modelo é conhecido como guarda comum ou

\footnotetext{
${ }^{3}$ SILVA, De Plácido. Vocabulário jurídico.4 ed. Rio de Janeiro: Forense, 1994, p. 365-366.

${ }^{4}$ Art. 1.634, inciso II, Código Civil: Compete aos pais, quanto à pessoa dos filhos menores: II- tê-los em sua companhia e guarda.

${ }^{5}$ Art. 21, do Estatuto da Criança e do Adolescente: 0 pátrio poder será exercido, em igualdade de condições, pelo pai e pela mãe, na forma do que dispuser a legislação civil, assegurando a qualquer deles o direito de, em caso de discordância, recorrer à autoridade judiciária competente para a solução da divergência.

${ }^{6}$ Art. 22, do Estatuto da Criança e do Adolescente: Aos pais incumbe o dever de sustento, guarda e educação dos filhos menores, cabendo-lhes ainda, no interesse destes, a obrigação de cumprir as determinações judiciais.
} 
originária, em que ambos os genitores exercem plenamente todos os poderes decorrentes do poder familiar. Neste tipo de guarda, tanto o pai quanto a mãe são guardiões dos filhos.

Porém, a separação entre os casais é comum e muitas vezes se dá através de conflitos, em razão disso é que surge a importância do instituto da guarda, que segundo o art. 229, da Constituição Federal, visa assegurar a toda criança o direito de ter um guardião para protegê-la. ${ }^{7}$

Insta mencionar que a guarda também pode ser confiada a uma terceira pessoa, assim, é possível que o poder familiar permaneça com os pais e a guarda com um terceiro. ${ }^{8}$

Dentre as modalidades de guarda, o sistema denominando Uniparental ou Unilateral é considerado o mais utilizado em nosso ordenamento jurídico. Neste tipo de guarda, o menor fica com um dos pais em residência fixa, e ao outro genitor é conferido o direito de visitas.

Diante do art. $1.583, \S 2^{\circ}$, do Código Civil, a guarda unilateral será atribuída ao genitor que revele melhores condições para exercê-la e, objetivamente, mais aptidão para propiciar aos filhos afeto nas relações com o genitor e com o grupo familiar, saúde, segurança e educação.

No mais, segundo o $\S 3^{\circ}$ do dispositivo acima mencionado, a guarda unilateral obriga o pai ou a mãe que não a detenha a supervisionar os interesses dos filhos, além de deter o direito de visitas à prole. ${ }^{9}$

Pode-se considerar tal modalidade de guarda como desvantajosa, pois na maioria dos casos, o filho deseja estar ao lado de seu pai e de sua mãe de formas igualitárias, e não estar com um e visitar o outro.Desta forma, ocorre o afrontamento ao princípio do melhor interesse da criança.

Também há de se destacar o modelo de guarda denominado de Alternada, que se caracteriza pela possibilidade de cada um dos pais deterem a guarda do filho alternadamente durante certo período, de forma exclusiva, detendo a totalidade dos poderes/deveres que integram o poder paternal. No término do período, os papéis invertem-se.

\footnotetext{
${ }^{7}$ Art. 229, Constituição Federal:Os pais têm o dever de assistir, criar e educar os filhos menores (...).

${ }^{8}$ VIANA, Marco Aurélio S. Da guarda, da tutela e da adoção. Belo Horizonte: Del Rey, 1993, p. 38.

${ }^{9}$ Art. 1.589, Código Civil: 0 pai ou a mãe, em cuja guarda não estejam os filhos, poderá visitá-los e tê-los em sua companhia, segundo o que acordar com o outro cônjuge, ou for fixado pelo juiz, bem como fiscalizar sua manutenção e educação.
} 
Esta modalidade não está prevista legalmente no ordenamento jurídico brasileiro, entretanto merece destaque, haja vista sua constante confusão com outra modalidade de guardadenominada compartilhada, que serão mais bem abordadas no próximo capítulo.

Por fim, a Guarda Compartilhada ou Guarda Conjuntaconsiste na mais recente modalidade e encontra previsão legal no art. 1.538, do Código Civil, introduzida pela Lei ${ }^{\circ}$ 11.698 , de 13 de junho de 2008 , o $§ 1^{\circ}$, segunda parte deste mesmo artigo dispõe o seguinte:

Compreende-se por (...) guarda compartilhada a responsabilização conjunta e o exercício de direitos e deveres do pai e da mãe que não vivam sob o mesmo teto, concernentes ao poder familiar dos filhos comuns.

Constitui em um sistema no qual os filhos e pais separados mantêm uma convivência harmoniosa, e todas as decisões referentes à prole são tomadas em conjunto com a opinião de ambos os genitores.

\section{DIFERENÇAS ENTRE GUARDA ALTERNADA E GUARDA COMPARTILHADA}

Infelizmente, o conceito e até mesmo a aplicação da guarda compartilhada são muito confundidos com o instituto da guarda alternada, algo que é prejudicial àquela, pois o modelo de guarda alternada recebe muitas críticas pelo nosso ordenamento jurídico e, por consequência, não foi inserido na legislação brasileira.

A grande crítica relacionada à guarda alternada é quanto à pluralidade de lares a que a criança estará sujeita. Neste sistema, os filhos se revezarão entre as residências de seus genitores, conforme o tempo determinado por eles, podendo ser esta alternância diária, semanal, mensal, semestral ou até mesmo anual.

Porém, este revezamento causa instabilidade aos filhos, por resultar na perda da rotina da criança/adolescente, além dos grandiosos esforços prestados por eles para se adaptarem a esta situação. 
Complementando este entendimento, dispõe Eduardo de Oliveira Leite: “os riscos da instabilidade material e psicológica para a criança são tão consideráveis que, hoje, a guarda alternada é presumida contrária ao interesse do menor e esta presunção é irrefragável". ${ }^{10}$

A guarda alternada acaba por tutelar apenas os interesses dos pais, pois implica em exercício unilateral do poder familiar durante os períodos por eles determinados. Esta situação promove verdadeira divisão do menor, que convive cada tempo com um dos genitores em casas diferentes.

Tal situação impede que as crianças criem laços afetivos e emocionais com seus pais, pois quando se adaptam à convivência com um dos genitores, a guarda é transferida ao outro e vice-versa. ${ }^{11}$

A este respeito, afirma Ana Carolina Silveira Akael:

Cremos que a alternância entre lares e guardiões impede que ocorra a consolidação dos hábitos diários, da própria rotina existente nos ambientes familiares e dos valores daí decorrentes, tão importantes para a vida e desenvolvimento da prole. Da relação alternada entre pais ocorre um elevado número de mudanças, repetidas separações e reaproximações, propiciando uma instabilidade emocional e psíquica ao menor. ${ }^{12}$

Contrária à guarda alternada, o instituto da guarda compartilhada, não há modificação de lares, assim, o menor possuirá uma residência fixa, podendo ser a casa do pai ou da mãe, a critério deles e também da criança. Deste modo, os filhos poderão estabelecer sua rotina sem necessidade de constantes mudanças e adaptações exigidas pela guarda alternada.

Insta ressaltar que a guarda conjunta tutela os interesses da criança/adolescente, poisconsiste no exercício simultâneo do poder familiar, incentivando a manutenção do vínculo afetivo dos filhos com o genitor com quem não residam. ${ }^{13}$

0 grande diferencial da guarda compartilhada é quanto à responsabilidade dos pais. Estes agirão de forma conjunta a fim de tomar as melhores decisões sobre a vida de seus

\footnotetext{
${ }^{10}$ LEITE, Eduardo de Oliveira. Famílias monoparentais. São Paulo: Revista dos Tribunais, 1997, p. 259.

${ }^{11}$ AKAEL, Ana Carolina Silveira. Guarda compartilhada:um avanço para a família. 2. ed. São Paulo: Atlas, 2009, p. 94.

${ }^{12}$ AKAEL, Ana Carolina Silveira. Guarda compartilhada:um avanço para a família. 2. ed. São Paulo: Atlas, 2009, p. 94.

13 ALVES, Leonardo Barreto Moreira. A guarda compartilhada e a Lei n. 11.698/2008. Revista IOB de Direito de Família. ano IX. n. 51. Porto Alegre: Síntese, dez-jan 2009, p. 102.
} 
filhos, lembrando que tudo o que for referente à prole deverá passar pelo consentimento de ambos os genitores.

Conforme mencionado anteriormente, há uma prejudicial confusão entre guarda alternada e guarda compartilhada que pode ser notada pelo julgado abaixo transcrito:

ALTERNADA - INADIMISSÍVEL - PREJUÍZO À FORMAÇÃO DO MENOR - A guarda compartilhada pressupõe a existência de diálogo e consenso entre os genitores sobre a educação do menor. Além disso, guarda compartilhada torna-se utopia quando os pais residem em cidades distintas, pois aludido instituto visa à participação dos genitores no cotidiano do menor, dividindo direitos e obrigações oriundas da guarda. 0 instituto da guarda alternada não é admissível em nosso direito, porque afronta o princípio basilar do bem estar do menor, uma vez que compromete a formação da criança, em virtude da instabilidade de seu cotidiano. Recurso desprovido. ${ }^{14} \mathrm{~g} . \mathrm{n}$

Percebe-se, pelo julgamento acima transcrito, o embaraço feito entre uma modalidade de guarda e outra, pois seria inviável a guarda alternada quando os pais moram distantes um do outro. Porém, quanto à guarda compartilhada, este não é um fator impeditivo, sendo possível que os genitores mantenham uma boa relação quanto à criação de seus filhos.

Além disso, sempre que admissível, os pais ou mães que não residam com seus filhos poderão estar fisicamente próximos da sua prole.

Realmente é lamentável este conflito de conceitos entre estas modalidades de guarda, nota-se a confusão feita pelo advogado Sigismundo Contijo:

Prejudicial para os filhos é a guarda compartilhada entre os pais separados. Esta resulta em verdadeiras tragédias, como tenho vivenciado ao participar, nas instâncias superiores, de separações judiciais oriundas de várias comarcas, em que foi praticada aquela heresia que transforma filhos emiô-iôs, ora com a mãe, ora com o pai. Em todos os processos ressaltam os grandes prejuízos dos menores, perdendo o referencial de "lar", sua perplexidade no conflito das orientações diferenciadas no meio materno e no paterno. Não é preciso ser psicólogo ou psicanalista para concluir que, acordo envolvendo a guarda compartilhada dos filhos, não é recomendável. ${ }^{15}$

\footnotetext{
${ }^{14}$ MINAS GERAIS. Tribunal de Justiça de Minas Gerais. AC 1.0000.00.328063-3/000. Rel. Des. Lamberto Sant'Anna. Data da publicação 24 out. 2003.

15 CONTIJO, Sigismundo. Guarda de filhos. Pailegal, 22 de mai. 2003. Disponível em <http://www. pailegal.net/forum/viewtopic.php?t=756>. Acesso em: 20 mai. 2014.
} 
Acredita-se que esta confusão mencionada seja um dos fatores impeditivos para que a guarda compartilhada possa ser aplicada de forma mais ampla.

\section{PRINCÍPIO DO MELHOR INTERESSE DA CRIANÇA E DO ADOLESCENTE}

Este princípio é garantidor da efetivação dos direitos fundamentais da criança e do adolescente, tratando-se de uma franca materialização da teoria da proteção integral, presente no art. 227da Constituição Federal ${ }^{16}$ e art. $1^{\circ}$ do Estatuto da Criança e do Adolescente. ${ }^{17}$

Nota-se que a guarda compartilhada alcança o melhor interesse do menor, pois como consta neste estudo, as inúmeras vantagens proporcionadas pela guarda conjunta faz com que os interesses dos filhos estejam amparados, pois a harmonia entre os genitores é o desejo de todas as crianças/adolescentes, além da necessidade da presença de ambos os pais em diversos momentos da vida dos filhos.

Contudo, caso não sejam seguidos os requisitos essenciais para a aplicação da guarda compartilhada, inúmeras desvantagens, que serão mencionadas mais à frente, poderão vir à tona ocasionando grande afetação ao princípio do melhor interesse do menor, pois em primeiro momento, os filhos querem manter contato aprofundado com seus genitores, o que é recomendável. Porém, caso este contato proporcionado pela guarda compartilhada seja desastroso, o melhor interesse da criança também não será cumprido.

\section{VANTAGENS DA GUARDA COMPARTILHADA}

É importante ressaltar que a guarda compartilhada só trará vantagens caso haja perfeita harmonia na relação entre os genitores. Pois, todas as decisões acerca da vida dos filhos deverão ser tomadas em conjunto, além de serem consentidas tanto pelo pai como pela mãe.

\footnotetext{
${ }^{16}$ Art. 227, Constituição Federal: É dever da família, da sociedade e do Estado assegurar à criança e ao adolescente, com absoluta prioridade, o direito à vida, à saúde, à alimentação, à educação, ao lazer, àprofissionalização, à cultura, à dignidade ao respeito, à liberdade e à convivência familiar e comunitária, além de colocá-los a salvo de toda forma de negligência, discriminação, exploração, violência, crueldade e opressão.

${ }^{17}$ Art. $1^{\circ}$, do Estatuto da Criança e do Adolescente: Esta Lei dispõe sobre a proteção integral à criança e ao adolescente.
} 
Sendo os pais capazes de se comportarem adequadamente, este gesto refletirá de forma positiva em seus filhos.

Desta forma, ao invés de prevalecer o desentendimento entre os genitores, causando grande abalo psicológico e até mesmo físico aos filhos, haverá com a guarda compartilhada, devidamente aplicada, melhor desenvolvimento da prole, não causando traumas com a brusca ruptura do modelo de família que antes o menor vivia.

Uma das grandes vantagens que compõem a guarda compartilhada é a não imposição dos filhos à escolha por um dos pais como guardião, sendo tal decisão motivo de angústia e desgaste emocional para aqueles, em virtude do medo de magoar o genitor que não foi o escolhido.

Ao contrário das outras modalidades de guarda, a compartilhada atribui isonomia aos pais, pois estes terão direitos e deveres de forma igualitária em relação aos filhos, devendo todas as decisões serem tomadas em conjunto, além de se estabelecer uma relação continuada entre os genitores e os filhos.

Deirdre de A. Neiva destaca o objetivo da fixação da guarda compartilhada:

\begin{abstract}
A guarda compartilhada almeja assegurar o interesse do menor, com o fim de protegê-lo, e permitir o seu desenvolvimento e a sua estabilidade emocional, tornando-o apto à formação equilibrada de sua personalidade, busca-se diversificar as influências que atuam amiúde na criança, ampliando o seu espectro de desenvolvimento físico e moral, a qualidade de suas relações afetivas e a sua inserção no grupo social. Busca-se, com efeito, a completa e a eficiente formação sociopsicológica, ambiental, afetiva, espiritual e educacional do menor cuja guarda se compartilha. ${ }^{18}$
\end{abstract}

Desta forma, fica evidenciado que através deste modelo de guarda, os sentimentos de culpa e frustração do genitor não guardião, pela ausência de cuidados em relação aos filhos, são diminuídos de forma significante.

No mais, a guarda compartilhada também se mostra vantajosa por ter mais força para manter a equivalência autoritária dos pais guardiães sobre o filho. Além do fato de o filho ter o referencial tanto de pai como de mãe, presentes e participativos, o que contribui para a melhor estabilidade emocional e a compreensão das regras de comportamento.

Com este mesmo entendimento, dispõe Ricardo Rodrigues Gama:

\footnotetext{
${ }^{18}$ NEIVA, Deirdre de A. Guarda compartilhada e alternada. Pai Legal, 7 de jan. 2002. Disponível em: <http://www. pailegal.net/guarda-compartilhada/mais-a-fundo/analises/68-a-guarda-compartilhada-ealternada>. Acesso em: 20 mai. 2014.
} 
Consistência emocional: a solidez sentimental contribui com a formação dos filhos e faz deles cidadãos capazes de discernir os abismos das regras de boa convivência no meio social e jurídico. Na formação da personalidade do menor, o pai imprime os referenciais masculinos e a mãe expõe os toques femininos, compondo o universo sentimental num padrão de estabilidade. ${ }^{19}$

Além disso, há comprovações de que o desenvolvimento psicoemocional das crianças cuja guarda é compartilhada é de grau mais elevado do que as que desfrutam da guarda unilateral, sendo aquelas mais calmas e pacientes.

A guarda compartilhada implica a cooperação entre os genitores, criando-se uma esfera de segurança e proteção em relação aos filhos, o que contribui para seu saudável desenvolvimento. Esta relação entre pai, mãe e filho é sempre preferível para a criança.Desta forma, a guarda compartilhada é o instituto que melhor atende as necessidades da prole.

\section{DESVANTAGENS DA GUARDA COMPARTILHADA}

Como todo plano de cuidado parental, a guarda compartilhada apresenta problemas sensíveis.

Conforme destacado no título anterior, uma das principais vantagens elencadas foi quanto à harmonia existente entre os pais, o que faz com que os filhos se sintam melhor e tenham maior desempenho em seu desenvolvimento.

Entretanto, é muito comum nos casos de separação haver discussões entre os genitores por causa dos conflitos conjugais e, muitas vezes, estas discussões são agravadas quando não se chega a um consenso com relação à guarda dos filhos.

Assim, caso o instituto da guarda compartilhada venha a ser imposto pelo magistrado sem o consenso dos genitores ou até mesmo com este, mas entre pais que vivam em constante discussão, esta experiência poderá ser desastrosa.

Os genitores que disputam constantemente e não cooperam para o cuidado dos filhos contaminam a educação destes, tornando impossível qualquer tipo de diálogo e transformando em uma verdadeira catástrofe a aplicação da guarda conjunta.

${ }^{19}$ GAMA, Ricardo Rodrigues. Guarda compartilhada: lei n. 11.698, de 13 de junho de 2008. Campinas: LZN, 2008. p. 53. 
Caso os pais vivam em constantes conflitos, não conseguindo estabelecer uma boa convivência nem em relação aos filhos, este modelo de guarda só irá aumentar os malefícios causados à prole, pela separação.

Normalmente, os fatores que levam os casais ao divórcio são, em regra, desentendimentos, brigas conjugais, falta de diálogo, entre outros. Todavia, dificilmente após a separação, estes casais conseguirão manter uma boa convivência para juntos decidirem sobre seus filhos. Nestas situações, o modelo recomendável é o uniparental.

Percebe-se que, basicamente, as desvantagens da guarda compartilhada se baseiam nas dificuldades dos genitores manterem um bom relacionamento, a fim de tomarem as melhores decisões acerca da vida dos filhos.

Nota-se também que são maiores as vantagens às desvantagens, pois aquelas atendem ao melhor interesse da criança/adolescente, podendo proporcionar a elesmelhor formação física, mental e moral, além de trazer grandes benefícios aos pais que estarão mais presentes e participativos na vida de seus filhos.

Cabe ao magistrado aplicar o melhor para o bem estar dos filhos menores, devendo analisar cada caso em particular, mesmo com os aspectos negativos da guarda compartilhada, prevalecem os pontos positivos. Desta forma, apenas em casos concretos saberá se esta modalidade de guarda é vantajosa ou não.

\section{ALIENAÇÃO PARENTAL}

A Alienação Parental, também conhecida como “implantação de falsas memórias" 20 , surge comumente durante as disputas pela guarda dos filhos, decorrente da ruptura da vida conjugal.

Geralmente, o genitor que não aceita o fim do relacionamento, por se sentir abandonado, rejeitado e traído, desencadeia um processo de destruição e desmoralização contra o ex-companheiro, ocasionando a Alienação Parental.

No ano de 2010, foi criada a Lei $n^{\circ} 12.138 / 2010$, que trata da Alienação Parental e aplica sansões para os alienantes.

\footnotetext{
20 RABELO, César Leandro de Almeida; VIEGAS, Cláudia Mara de Almeida Rabelo. Aspectos materiais e processuais da alienação parental.Revista Síntese Direito de Família.v. 14. n. 75. São Paulo, dez./jan. 2013, p. 27.
} 
0 art. $2^{\circ}$, caput, da Lei conceitua a Alienação Parental da seguinte forma:

Considera-se ato de alienação parental a interferência na formação psicológica da criança ou do adolescente promovida ou induzida por um dos genitores, pelos avós ou pelos que tenham a criança ou adolescente sob a sua autoridade, guarda ou vigilância para que repudie genitor ou que cause prejuízo ao estabelecimento ou à manutenção de vínculos com este.

Conforme dispõe o artigo acima transcrito, o ato de alienação parental pode ser cometido por um dos genitores, bem como por qualquer outra pessoa que detenha a criança ou adolescente sob sua autoridade, guarda ou vigilância.

Embora qualquer dos genitores possa praticar alienação parental para com o filho, é comum que o alienante seja o genitor guardião, que se encontra em vantagem ao genitor que possui apenas o direito de visitas.

O parágrafo único do art. $2^{\circ}$ exemplifica as formas de alienação parental:

I - realizar campanha de desqualificação da conduta do genitor no exercício da paternidade ou maternidade;

II - dificultar o exercício da autoridade parental;

III - dificultar contato de criança ou adolescente com genitor;

IV - dificultar o exercício do direito regulamentado de convivência familiar;

$\mathrm{V}$ - omitir deliberadamente a genitor informações pessoais relevantes sobre a criança ou adolescente, inclusive escolares, médicas e alterações de endereço;

$\mathrm{VI}$ - apresentar falsa denúncia contra genitor, contra familiares deste ou contra avós, para obstar ou dificultar a convivência deles com a criança ou adolescente;

VII - mudar o domicílio para local distante, sem justificativa, visando a dificultar a convivência da criança ou adolescente com o outro genitor, com familiares deste ou com avós.

A prática destes atos de alienação parental, quando não identificados e tratados, pode ocasionar a chamada Síndrome da Alienação Parental.

O termo Síndrome de Alienação Parental (SAP) foi proposto pelo psicanalista infantil Richard Gardner, em 1985. A SAP é definida como um distúrbio que aparece 
principalmente no contexto da disputa da guarda dos filhos pelos pais, e tem como primeira manifestação uma campanha de difamação contra um dos genitores por parte da criança. ${ }^{21}$

Com a finalidade de esclarecer as diferenças entre SAP e Alienação Parental, seguem as palavras da professora Priscila M.P. Correa Fonseca:

A síndrome da alienação parental não se confunde, portanto, com a mera alienação parental. Aquela geralmente é decorrente desta, ou seja, a alienação parental é o afastamento do filho de um dos genitores, provocado pelo outro, via de regra, o titular da custódia. A síndrome, por seu turno, diz respeito às seqüelas emocionais e comportamentais de que vem a padecer a criança vítima daquele alijamento. Assim, enquanto a síndrome refere-se à conduta do filho que se recusa terminante e obstinadamente a ter contato com um dos progenitores e que já sofre as mazelas oriundas daquele rompimento, a alienação parental relaciona-se com o processo desencadeado pelo progenitor que intenta arredar o outro genitor da vida do filho. 22

A Síndrome de Alienação Parental diz respeito aos efeitos emocionais e às condutas comportamentais desencadeados na criança que é ou foi vítima do processo de alienação parental, ou seja, são as sequelas deixadas pela alienação.

Assim, ilustra Maria Berenice Dias:

O filho é convencido da existência de um fato e levado a repetir o que the é afirmado como tendo realmente acontecido. Nem sempre a criança consegue discernir que está sendo manipulada e acaba acreditando naquilo que thes foi dito de forma insistente e repetida. Com o tempo, nem a mãe consegue distinguir a diferença entre verdade e mentira. A sua verdade passa a ser verdade para o filho, que vive com falsas personagens de uma falsa existência, implantando-se, assim, falsas memórias. ${ }^{23}$

Os efeitos provocados pela SAP podem ser devastadores, ocasionando anormalidade no desenvolvimento psíquico da criança/adolescente, ansiedade, depressão

${ }^{21}$ GARDNER, Richard. O DSM-IV tem equivalente para o diagnóstico de síndrome de alienação parental (SAP)? Trad. Rita Rafaeli.SAP, 2002. Disponível em: <http://www.alienacaoparental.com.br/textos-sobresap-1/o-dsm-iv-tem-equivalente>. Acesso em: 19 mai. 2014.

${ }_{22}^{2}$ FONSECA, Priscila M. P. Corrêa da. Síndrome da alienação parental. Revista Brasileira de Direito de Família. v. 8, n. 40, fev/mar. 2007.

${ }^{23} \mathrm{DIAS}$, Maria Berenice. Síndrome da alienação parental, o que é isso?. Jus Navigandi, Disponível em: <http://jus.com.br/artigos/8690>. Acesso em: 19 mai. 2014. 
crônica, nervosismo, agressão, transtorno de identidade, incapacidade de adaptação ao ambiente normal, dentre outros.

Deste modo, quando houver indícios da prática de alienação parental, o órgão judiciário, acionado pelo genitor vítima da alienação, pelo Ministério Público ou, mesmo de ofício, poderá determinar perícia psicológica ou biopsicossocial para averiguar se realmente há alienação parental, bem como determinar provisoriamente as medidas processuais previstas na Lei de Alienação Parental.

Assim, quando identificada a prática de Alienação Parental, através do art. 6º 0 juiz poderá:

I - declarar a ocorrência de alienação parental e advertir o alienador;

II - ampliar o regime de convivência familiar em favor do genitor alienado;

III - estipular multa ao alienador;

IV - determinar acompanhamento psicológico e/ou biopsicossocial;

V - determinar a alteração da guarda para guarda compartilhada ou sua inversão;

VI - determinar a fixação cautelar do domicílio da criança ou adolescente;

VII - declarar a suspensão da autoridade parental.

Parágrafo único: Caracterizado mudança abusiva de endereço, inviabilização ou obstrução à convivência familiar, o juiz também poderá inverter a obrigação de levar para ou retirar a criança ou adolescente da residência do genitor, por ocasião das alternâncias dos períodos de convivência familiar.

A decretação destas sanções pode ocorrer através de ação autônoma ou mesmo incidentalmente em processos que já discutam a relação dos filhos, como por exemplo, em uma ação de guarda, regulamentação de visitas, fixação de alimentos e principalmente em ações de divórcio.

\section{GUARDA COMPARTILHADA COMO FORMA DE INIBIR A ALIENAÇÃO PARENTAL}

Conforme visto no título anterior, acredita-se que o surgimento da alienação parental ocorre em situações na qual os genitores disputam a guarda de seus filhos e, 
consequentemente, por não haver um consenso entre estes pais, há uma imposição de guarda unilateral, o que pode agravar a prática da alienação.

Segundo dispõe o art. $6^{\circ}$ da Lei 12.318/2010, que trata da alienação parental, uma das medidas cabíveis para inibir ou atenuar os efeitos da dita alienação é, segundo o inciso $V$, determinar a alteração da guarda para guarda compartilhada.

Esta sanção está intimamente relacionada com o fato de os atos de alienação parental predominarem nas disputas de guarda, seja esta disputa em ações de divórcio ou nas ações de guarda propriamente dita.

Em um contexto, no qual grande parte das práticas de alienação parental ocorre pela imposição de guarda unilateral, em que a criança/adolescente ficará com apenas um dos genitores, restando ao outro genitor apenas o direito de visitas, ou seja, uma menor aproximação para com seus filhos, defende-se que a guarda compartilhada seria o ideal para inibir a alienação parental, pois não haveria disputa entre os genitores com relação aos filhos.Com esta guarda, os filhos teriam sempre a presença de ambos os pais, o que diminuiria a influência de apenas um genitor sobre a prole dificultando, assim, a alienação parental.

Pode-se afirmar com certeza que a guarda compartilhada, em que a criança/adolescente tem sempre ao seu redor ambos os genitores, e estes decidem conjuntamente sobre o que é melhor para seus filhos, é a modalidade de guarda que atinge o princípio do melhor interesse da criança/adolescente.

Entretanto, não se pode esquecer-se do que fora mencionado anteriormente neste artigoa respeito da aplicação da guarda compartilhada que exige, antes de tudo, um bom relacionamento entre os pais, para que possa predominar o diálogo, e que as decisões a respeito de tudo que envolva os filhos sejam tomadas em conjunto.

E mais, caso a guarda compartilhada seja aplicada sem o consentimento dos pais (de ofício) ou mesmo com o consentimento destes, porém sem que sejam preenchidos todos os requisitos para a aplicação da mesma, todas as desvantagens desta modalidade de guarda poderão vir à tona, gerando prejuízos ao principal sujeito desta história, o filho.

Assim, surge a pergunta que não cala, como pode a guarda compartilhada ser imposta para inibir a alienação parental, sendo que o surgimento desta alienação se dá justamente por haver rancor entre os genitores, chegando ao ponto de um deles denegrir a imagem do outro e embutir falsas memórias na mente do seu próprio filho para que este passe a repudiar o outro genitor? 
Pode-se afirmar que 0 ato de alienação parental em si rompe qualquer possibilidade de ser aplicada a guarda compartilhada.

No entanto, é importante ressaltar que a todo o momento não se deve esquecer que os principais sujeitos de toda esta disputa são os filhos. Desta forma, os casos devem ser analisados de forma individualizada, com a finalidade de atingir o princípio do melhor interesse da criança/adolescente em sua plenitude.

Portanto, mesmo havendo a incidência de alienação parental, e após a análise de todos os fatos em um caso concreto, chega-se a conclusão certeira de que a guarda compartilhada é a melhor opção. A mesma pode ser aplicada, contudo, recomenda-se que seja feito com certa desconfiança.

\section{CONCLUSÃO}

Conforme dito no início deste artigo, o Direito de Família tem se inovado cada vez mais com o intento de acompanhar as transformações dos modelos de família contemporânea.

Uma destas inovações foi a regulamentação da guarda compartilhada pela legislação brasileira, haja vista que esta modalidade de guarda já era utilizada pelo judiciário, entretanto sem fundamentação legal.

A legislação assegura que a guarda compartilhada será aplicada sempre que possível, haja vista que este modelo de guarda é o que atende o princípio do melhor interesse da criança e do adolescente.

A principal característica da guarda compartilhada é quanto à responsabilidade dos pais, pois estes agirão de forma conjunta a fim de tomar as melhores decisões sobre a vida de seus filhos, lembrando que tudo o que for referente à prole deverá passar pelo consentimento de ambos os genitores.

Embora a guarda conjunta seja o modelo recomendado, é a guarda unilateral a modalidade de maior aplicabilidade, mesmo não atingindo o melhor interesse da criança e do adolescente. 
Tal situação se dá pela falta dos requisitos necessários para a aplicação da guarda compartilhada, que exige perfeita harmonia na relação entre os genitores para que estes possam compartilhar todos os direitos e deveres relacionados à prole.

Sabe-se que em grande parte dos divórcios ou rompimentos, ao invés de permanecer a amizade entre os ex-consortes, o que prevalece são os desentendimentos e a disputa pela guarda dos filhos.

É neste contexto que surgem os casos de Alienação Parental, que tem como primeira manifestação uma campanha de difamação contra um dos genitores por parte da criança, lembrando que normalmente, o genitor alienante é o detentor da guarda unilateral.

Também foi visto neste trabalho que a lei que trata da alienação parental traz, como forma de inibir os atos de alienação, a modificação da guarda unilateral para a guarda compartilhada.

Entretanto, com base nas exposições anteriores, conclui-se que esta não é a medida mais adequada, pois o ato de alienação parental em si rompe qualquer possibilidade de ser aplicada a guarda compartilhada.

Caso haja a imposição de guarda compartilhada, neste contexto poderá agravar ainda mais a Síndrome de Alienação Parental, que pode provocar sequelas irreversíveis ao infante.

No entanto, é importante lembrar que o principal sujeito de toda esta disputa é o filho. Assim, os casos devem ser analisados de forma individualizada, com a finalidade de atingir o princípio do melhor interesse da criança/adolescente em sua plenitude.

\section{REFERÊNCIAS}

AKAEL, Ana Carolina Silveira. Guarda compartilhada: um avanço para a família. 2. ed. São Paulo: Atlas, 2009.

ALVES, Leonardo Barreto Moreira. A guarda compartilhada e a Lei n. 11.698/2008. Revista IOB de Direito de Família.ano IX. n. 51. Porto Alegre: Síntese, dez-jan 2009. 
AMARAL, Paulo André. Guarda compartilhada, igualdade de gênero e justiça no brasil: uma análise das interpretações da lei. Revista Brasileira de Direito de Família e Sucessões. Porto Alegre: Magister; Belo Horizonte: IBDFam, a. 14, n. 32. fev. e mar. 2013.

CONTIJO, Sigismundo. Guarda de filhos. Pai Legal, 22 de mai. 2003. Disponível em <http://www.pailegal.net/forum/viewtopic.php?t=756>. Acesso em: 20 de maio de 2014.

DIAS, Maria Berenice. Síndrome da alienação parental, o que é isso?. Jus Navigandi. Disponível em: <http://jus.com.br/artigos/8690/sindrome-da-alienacao-parental-o-que-e-isso>. Acesso em: 19 mai. 2014.

DINIZ, Maria Helena. Curso de direito civil brasileiro: direito de família. v.5. 25. ed. São Paulo: Saraiva, 2010.

FONSECA, Priscila M. P. Corrêa da. Síndrome da alienação parental. Revista Brasileira de Direito de Família. v. 8, n. 40, fev/mar. 2007.

GAMA, Guilherme Calmon Nogueira. Princípios constitucionais de direito de família. São Paulo: Atlas, 2008.

GAMA, Ricardo Rodrigues. Guarda compartilhada: lei n. 11.698, de 13 de junho de 2008. Campinas: LZN, 2008.

GARDNER, Richard. O DSM-IV tem equivalente para o diagnóstico de síndrome de alienação parental (SAP)? Trad. Rita Rafaeli. SAP, 2002. Disponível em:

<http://www.alienacaoparental.com.br/textos-sobre-sap-1/o-dsm-iv-tem-equivalente>. Acesso em: 19 mai. 2014.

GROENINGA, Giselle Câmara; PEREIRA, Rodrigo da Cunha. Família: um caleidoscópio de relações, em direito de família e psicanálise, rumo a uma nova epistemologia. Rio de Janeiro: IMAGO, 2008.

LEITE, Eduardo de Oliveira. Famílias monoparentais. São Paulo: Revista dos Tribunais, 1997.

NEIVA, Deirdre de A. Guarda compartilhada e alternada. Pai Legal, 7 de jan. 2002. Disponível em: <http://www.pailegal.net/guarda-compartilhada/mais-a-fundo/analises/68-a-guardacompartilhada-e-alternada>. Acesso em: 20 mai. 2014. 
ISSN 1981-3694

(DOI): $10.5902 / 1981369414772$

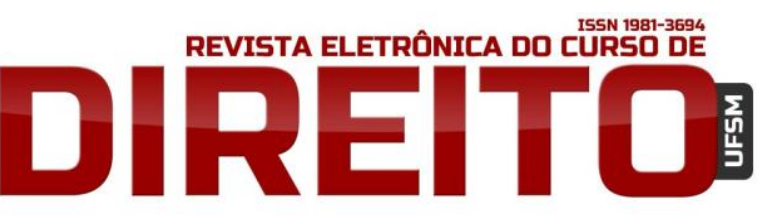

GUARDA COMPARTILHADADA: UM CAMINHO PARA INIBIR A ALIENAÇÃO PARENTAL?

EDWIRGES ELAINE RODRIGUES, MARIA AMÁLIA DE FIGUEIREDO PEREIRA ALVARENGA

PARREIRA, Ana Carolina Rodrigues.A alienação parental e sua relação com o direito de família. In:ALVARENGA, Maria Amália de Figueired Pereira. Os novos parâmetros da responsabilidade civil e as relações sociais. Franca: Unesp, 2012.

RABELO, César Leandro de Almeida; VIEGAS, Cláudia Mara de Almeida Rabelo. Aspectos materiais e processuais da alienação parental.Revista Síntese Direito de Família.v. 14. n. 75. São Paulo, dez./jan. 2013.

SILVA, De Plácido. Vocabulário jurídico. 4 ed. Rio de Janeiro: Forense, 1994.

VIANA, Marco Aurélio S. Da guarda, da tutela e da adoção. Belo Horizonte: Del Rey, 1993.

VIEIRA, Patrício Jorge Lobo. O dano moral na alienação parental.Revista Brasileira de Direito de Família e Sucessões. Porto Alegre: Magister; Belo Horizonte: IBDFam, a. 14, n. 31. dez. e jan. 2013.

Recebido em: 09/07/2014 / Revisado em: 03/11/2014 Aprovado em: 20/11/2014 